\title{
The Value of PIC Cystography in Detecting De Novo and Residual Vesicoureteral Reflux after Dextranomer/Hyaluronic Acid Copolymer Injection
}

\author{
B. W. Palmer, M. Hemphill, K. Wettengel, B. P. Kropp, and D. Frimberger \\ Section of Pediatric Urology, Department of Urology, University of Oklahoma Health Sciences Center, 920 Stanton L. Young Blvd, \\ WP-3150, Oklahoma City, OK 73104, USA \\ Correspondence should be addressed to D. Frimberger, dominic-frimberger@ouhsc.edu
}

Received 28 January 2011; Revised 1 April 2011; Accepted 6 May 2011

Academic Editor: Michael J. Ross

Copyright () 2011 B. W. Palmer et al. This is an open access article distributed under the Creative Commons Attribution License, which permits unrestricted use, distribution, and reproduction in any medium, provided the original work is properly cited.

The endoscopic injection of Dx/HA in the management of vesicoureteral reflux (VUR) has become an accepted alternative to open surgery. In the current study we evaluated the value of cystography to detect de novo contralateral VUR in unilateral cases of VUR at the time of Dx/HA injection and correlated the findings of immediate post-Dx/HA injection cystography during the same anesthesia to 2-month postoperative VCUG to evaluate its ability to predict successful surgical outcomes. The current study aimed to evaluate whether an intraoperatively performed cystogram could replace postoperative studies. But a negative intraoperative cystogram correlates with the postoperative study in only $80 \%$. Considering the $75-80 \%$ success rate of Dx/HA implantation, the addition of intraoperative cystograms cannot replace postoperative studies. In patients treated with unilateral VUR, PIC cystography can detect occult VUR and prevent postoperative contralateral new onset of VUR.

\section{Introduction}

The role of endoscopic injection of dextranomer/hyaluronic acid copolymer (Dx/HA) has expanded, as an alternative to open surgery, to a treatment option for observation protocols using prophylactic antibiotics. Deflux has been FDA approved since 2001 as a treatment option for grade 2-4 vesicoureteral reflux (VUR) in single systems with no accompanying urological malformations in children above one year of age. The operative ease of technique, short procedure, and recovery time as well as repeatability of injections have popularized the technique with surgeons and parents alike. Reports of expanded use to patients of all ages and grades of VUR even in the presence of duplication, ureterocele, or other lower tract anomalies are published worldwide $[1,2]$. In a statement of the AUA board of directors from October 2007, it was determined that: "It is the current position of the American Urological Association that endoscopic injection of the dextranomer/hyaluronic compound Deflux is an option in the management of pediatric vesicoureteral reflux (VUR)" [3, 4].
The initial success rate was quoted as $68 \%$ [5] and is still mentioned on the current website [6] of the manufacturing company (Q-MED, Scandinavia Inc). In the meantime, the original subureteric injection technique (STING) has evolved to the intraureteric injection technique introduced by the Atlanta group. Using this hydrodistentionimplantation technique (HIT), the authors reported success rates of $89 \%$ [7]. However, the reported worldwide success rates differ considerably $(55 \%-89 \%[7,8])$. Unpublished data from our institution show an overall radiographic success rate of $75 \%$ for patients and $84 \%$ for renal units after the first injection. These numbers include all grades of VUR and a variety of urological malformations. Although the success rates continuously improve, the numbers of most institutions still differ significantly from the traditional 98\% for open reimplants. Since up to $25 \%$ of patients will have remaining VUR after Dx/HA injection, we still perform voiding cystograms 2 months after surgery.

Positional instillation of contrast (PIC) cystography was developed to detect occult VUR in patients with recurrent urinary tract infections (UTI) after a negative standard 


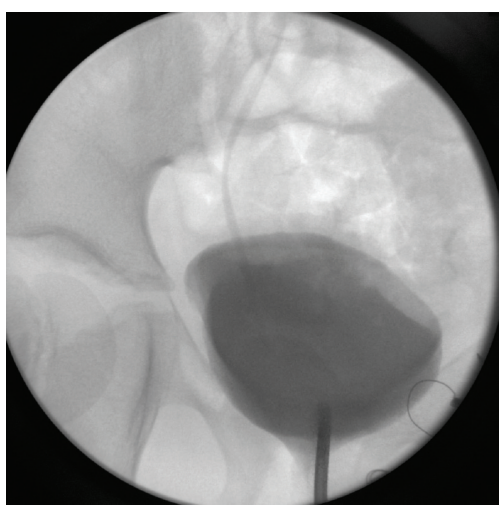

Figure 1: Positive unilateral HPC after Deflux injection showing residual VUR.

voiding cystogram. It has a higher sensitivity than standard voiding cystogram (VCUG) and can detect occult VUR [9]. Parents can be advised that in case of a positive PIC, Dx/HA injection can be performed during the same anesthesia. In the current study, we compared two different PIC techniques and evaluated two different scenarios: First, whether PIC cystography or high-pressure cystograms were useful to detect de novo contralateral VUR in the case of preoperative unilateral VUR and second, whether PIC cystography, when performed intraoperatively immediately after Dx/HA injection, can predict a successful surgical outcome by correlating the results with a standard 2-month postprocedure VCUG.

\section{Material and Methods}

A retrospective chart review was performed on all intraoperative cystograms performed at the time of $\mathrm{Dx} / \mathrm{HA}$ injections at our institution from 2005-2007. IRB approval was obtained. Dx/HA injections were performed for all grades of VUR and included complex cases such as duplicated systems. In case of preoperative unilateral reflux, a PIC cystogram was performed on the contralateral unaffected side before $\mathrm{Dx} / \mathrm{HA}$ injection. If positive, bilateral injection took place. If negative, only the affected side was treated. The injections were done using the HIT technique as described by Kirsch et al. [7]. Dx/HA was injected until a sufficient mound and good ureteral coaptation was observed. At this point a cystogram was performed. Two techniques for intraoperative cystograms were studied. The first group underwent a highpressure cystogram (Figure 1). The outflow portion of the 10 french off set cystoscope (Wolf, Germany) was placed at the bladder neck filling the bladder with contrast material (Cystografin) to $100 \mathrm{~cm}$ water pressure until voiding occurred around the cystoscope ensuring complete bladder filling. The second group underwent standard PIC cystography [8] with the outflow portion of the cystoscope directed at the ureteral orifice at a $100 \mathrm{~cm}$ water pressure for 5 seconds (Figure 2). Radiographic views for both tests were performed in anterior-posterior and lateral as well as upper tract views. The intraoperative cystogram was noted to be positive if any grade of VUR was present (Figure 3 ). In cases of a positive

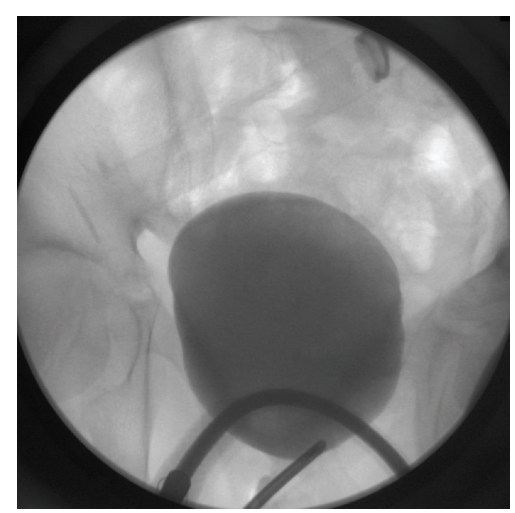

FIgURE 2: Negative unilateral PIC cystogram after Deflux injection showing resolution of VUR.

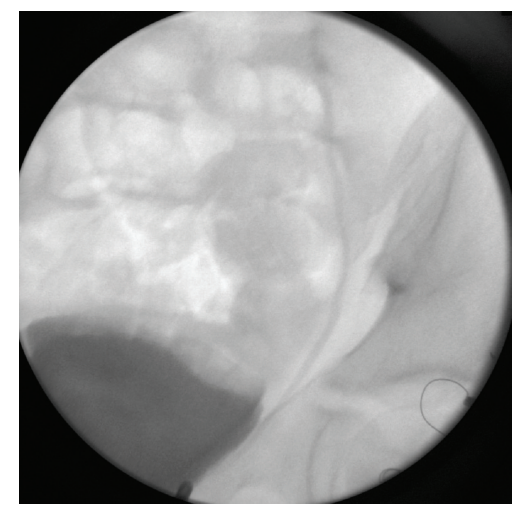

Figure 3: Positive unilateral positional infusion contrast (PIC) cystogram before Deflux injection showing de novo VUR.

study on the contralateral side or for remaining VUR after injection, Dx/HA was reinjected. The cystogram was then repeated until resolution of the VUR was seen. The patients were left on prophylactic antibiotics and followed up at 4 weeks postoperatively with an ultrasound and 2 months postoperatively with a VCUG. The correlations of the intraand postoperative study as well as the detection of de novo VUR were noted.

\section{Results}

Altogether 116 patients and 177 renal units (RU) were treated and available for evaluation. Out of the 116 patients, 34 were found preoperatively to have unilateral and 82 bilateral VUR. New contralateral VUR (de novo) for the 34 preoperative unilateral refluxing patients was found intraoperatively in 27 RU (Figure 4(c)). The high-pressure intraoperative cystogram (Group 1) was performed in 86 RUs and the standard PIC (Group 2) in 91 RUs. There was no statistically significant difference between groups 1 and 2 for the detection of de novo VUR (Figure 4(b)).

For both groups, only $5 \mathrm{RU}$ were found to have remaining VUR intraoperatively after Dx/HA injection (2 in Group 1 and 3 in Group 2). All 5 patients were reinjected and had a subsequent negative intraoperative cystogram. 


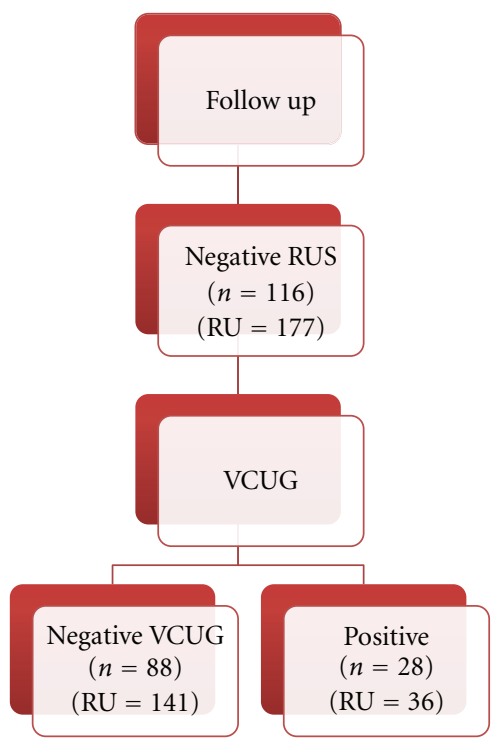

(a)

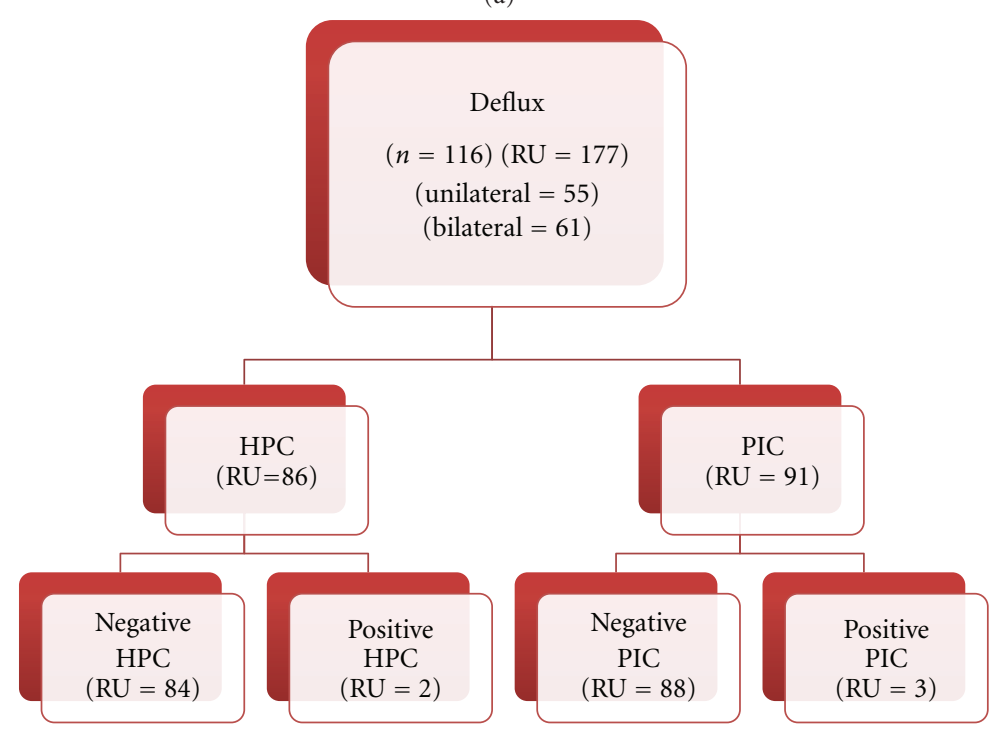

(b)

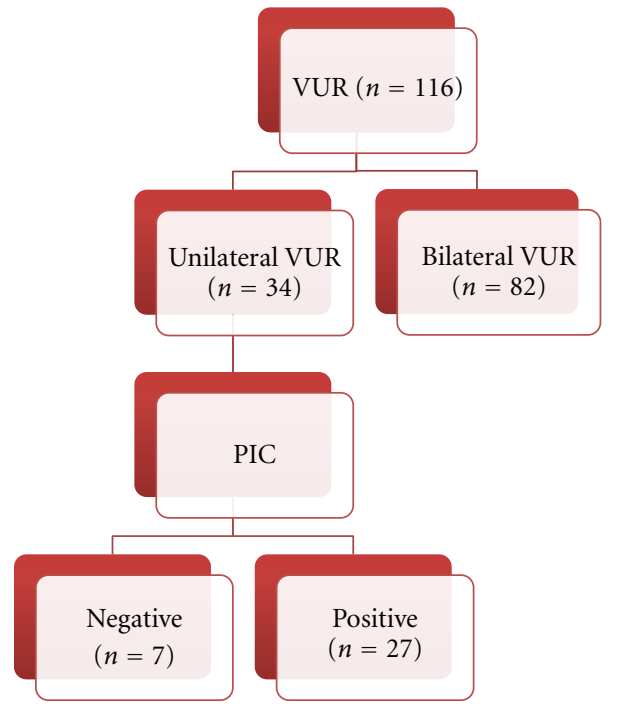

(c)

FIGURE 4 
No intra- or postoperative complications were noted. No patient had a UTI in the follow-up period. Postoperative pain management, if necessary, consisted of Ibuprofen or Acetaminophen according to parental preference. In all patients, the postoperative US at four weeks were negative for hydronephrosis or any other new abnormality. The Dx/HA deposits were seen in the bladder in all cases. At 2 months postoperative standard VCUG detected $20 \mathrm{RU}$ (23\%) to be positive for VUR in Group 1 and 16 RU (18\%) positive for VUR in Group 2. Altogether 36 RU were positive, for an allover success rate of $80 \%$ for RU and $75 \%$ for patients (Figure 4(a)). There was no statistical difference between the groups. The grade of VUR, age and gender of patient as well as amount of Deflux injected did not influence the result.

\section{Discussion}

Vesicoureteral reflux remains a common disease, and especially for lower grades the prospect of spontaneous resolution is good. But, the data on the value of daily prophylactic antibiotics remain controversial, and most parents are concerned about their long-term use. The discussion becomes evident by the current multi-institutional NIH-funded RIVUR study, which aims to evaluate the role of prophylactic antibiotic in VUR. In addition to prolonged antibiotic use, parents and patients alike dread the yearly necessary voiding cystogram to check for resolution. Therefore, to avoid the daily antibiotics and the yearly VCUG, many parents consider surgical treatment options. The endoscopic injection of $\mathrm{Dx} / \mathrm{HA}$ is an attractive management alternative for parents. When presenting the surgical options, all parents are enthusiastic about the minimal invasive nature of the procedure with low complication possibilities and fast recovery times. However, the $20 \%-25 \%$ lower success rate of the endoscopic procedure in comparison to the open surgery is a concern.

Although Dx/HA can be reinjected, it requires further testing, anesthesia, and time spent away from school or work. Therefore, it would be highly desirable to develop a method to check the success of the Deflux injection intraoperatively. PIC cystography is used to detect occult VUR in patients with a negative standard voiding study who suffer from recurrent UTIs. According to Rubenstein et al., the procedure is a $100 \%$ sensitive and $91 \%$ specific in identifying VUR and can, therefore, detect occult VUR [9]. Tareen et al. recently confirmed the findings in 5 patients [10]. In a study on 39 patients with febrile UTIs and negative voiding studies from 4 different institutions, PIC cystograms were performed and VUR identified in $82 \%$ of these patients. Additionally, the authors noted that orifices that were patulous, laterally displaced, or positive for hydrodistention were much more likely to be positive for VUR than normal orifices [11]. Pinto et al. also performed intraoperative PIC cystograms and found that $23 \%$ of patients had a positive, postoperative VCUG despite a negative intraoperative PIC study [12], and Palmer confirmed these results [13]. The authors concluded that PIC cystography was not useful to raise the success rate of Deflux injection.

In the current study, we used two different cystogram techniques: the standard PIC study and a high-pressure cystogram, filling the bladder until irrigation fluid leaked around the cystoscope. Even with this aggressive cystogram technique only an $80 \%$ correlation between a negative intraoperative cystogram and postoperative cystogram was achieved. The success rate of $75 \%$ for patients and $80 \%$ for RU could not be improved. Several reasons for the intraoperative negative study are possible. At time of injection a relative wound edema might increase the coaptation of the ureteral orifice, temporarily giving a negative intraoperative study result. Other possibilities include decrease in the size of the injected $\mathrm{Dx} / \mathrm{HA}$ deposit over time, also thought to be responsible for long-term failure after Dx/HA injection [14]. Finally, Dx/HA deposits can migrate from their injected position. This phenomenon has been noted during cystoscopy at the time of the planned second injection of Deflux after initial failure. The Dx/HA deposits tend to migrate medially and toward the bladder neck causing long-term failure of injection.

Elmore et al. reported the onset of new contralateral VUR after Dx/HA implantation in approximately $13 \%$ of 126 patients with preoperatively unilateral VUR [15]. In the current study, 34 out of 116 patients were preoperatively diagnosed with unilateral VUR only. Twenty seven of these 34 patients demonstrated a positive PIC cystography intraoperatively and were successfully injected with Dx/HA. None of these de novo detected refluxing units were positive for VUR in the postoperative cystograms.

\section{Conclusion}

A negative intraoperative cystogram correlates with the postoperative VCUG in only $80 \%$. Considering that the success rates of $\mathrm{Dx} / \mathrm{HA}$ injections are commonly between $75-80 \%$, the addition of intraoperative cystograms cannot replace postoperative studies. In patients treated with unilateral VUR, PIC cystography can detect occult reflux and prevent postoperative contralateral new onset of VUR.

\section{References}

[1] P. A. Merguerian, A. Taenzer, K. Knoerlein, L. McQuiston, and D. Herz, "Variation in management of duplex system intravesical ureteroceles: a survey of pediatric urologists," The Journal of Urology, vol. 184, no. 4, pp. 1625-1630, 2010.

[2] T. W. Hensle, E. A. Reiley, C. Ritch, and A. Murphy, "The clinical utility and safety of the endoscopic treatment of vesicoureteral reflux in patients with duplex ureters," Journal of Pediatric Urology, vol. 6, no. 1, pp. 15-22, 2010.

[3] http://www.auanet.org/content/guidelines-and-quality-care/ policy-statements/u/use-of-Deflux $囚$-in-the-management-of -vesicoureteral-reflux.cfm.

[4] C. A. Peters, S. J. Skoog, B. S. Arant et al., "Summary of the AUA guideline of management of primary vesicoureteral reflux in children," The Journal of Urology, vol. 184, no. 3, pp. 1134-1144, 2010.

[5] G. Läckgren, N. Wåhlin, E. Sköldenberg et al., "Long-term followup of children treated with dextranomer/hyaluronic acid copolymer for vesicoureteral reflux," The Journal of Urology, vol. 166, no. 5, pp. 1887-1892, 2001.

[6] http://www.deflux.com/country/usa/?q=node/24/accessdate/ 6/20/2011. 
[7] A. J. Kirsch, M. Perez-Brayfield, E. A. Smith, and H. C. Scherz, "The modified sting procedure to correct vesicoureteral reflux: improved results with submucosal implantation within the intramural ureter," The Journal of Urology, vol. 171, no. 6, pp. 2413-2416, 2004.

[8] U. Altug, M. Cakan, S. Yilmaz, and F. Yalçinkaya, "Are there predictive factors for the outcome of endoscopic treatment of grade III-V vesicoureteral reflux with dextranomer/hyaluronic acid in children?" Pediatric Surgery International, vol. 23, no. 6, pp. 585-589, 2007.

[9] J. N. Rubenstein, M. Maizels, S. C. Kim, and J. T. B. Houston, "The pic cystogram: a novel approach to identify "occult" vesicoureteral reflux in children with febrile urinary tract infections," The Journal of Urology, vol. 169, no. 6, pp. 23392343, 2003.

[10] B. U. Tareen, D. Bui, D. R. McMahon, and P. F. Nasrallah, "Role of positional instillation of contrast cystography in the algorithm for evaluating children with confirmed pyelonephritis," Urology, vol. 67, no. 5, pp. 1055-1057, 2006.

[11] J. D. Edmondson, M. Maizels, S. A. Alpert et al., "Multiinstitutional experience with PIC cystography-incidence of occult vesicoureteral reflux in children with febrile urinary tract infections," Urology, vol. 67, no. 3, pp. 608-611, 2006.

[12] K. J. Pinto, J. Pugach, and J. Saalfield, "Lack of usefulness of positioned instillation of contrast cystogram after injection of dextranomer/hyaluronic acid," The Journal of Urology, vol. 176, no. 6, pp. 2654-2656, 2006.

[13] L. S. Palmer, "The role of intraoperative cystography following the injection of dextranomer/hyaluronic acid copolymer," The Journal of Urology, vol. 179, no. 3, pp. 1118-1121, 2008.

[14] A. Stenberg and G. Lackgren, "A new bioimplant for the endoscopic treatment of vesicoureteral reflux: experimental and short-term clinical results," The Journal of Urology, vol. 154, no. 2, pp. 800-803, 1995.

[15] J. M. Elmore, A. J. Kirsch, R. H. Lyles, M. R. PerezBrayfield, and H. C. Scherz, "New contralateral vesicoureteral reflux following dextranomer/hyaluronic acid implantation: incidence and identification of a high risk group," The Journal of Urology, vol. 175, no. 3, pp. 1097-1100, 2006. 


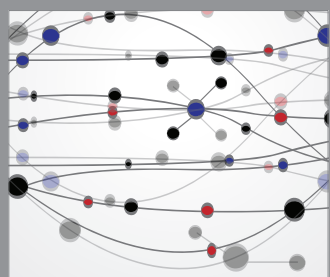

The Scientific World Journal
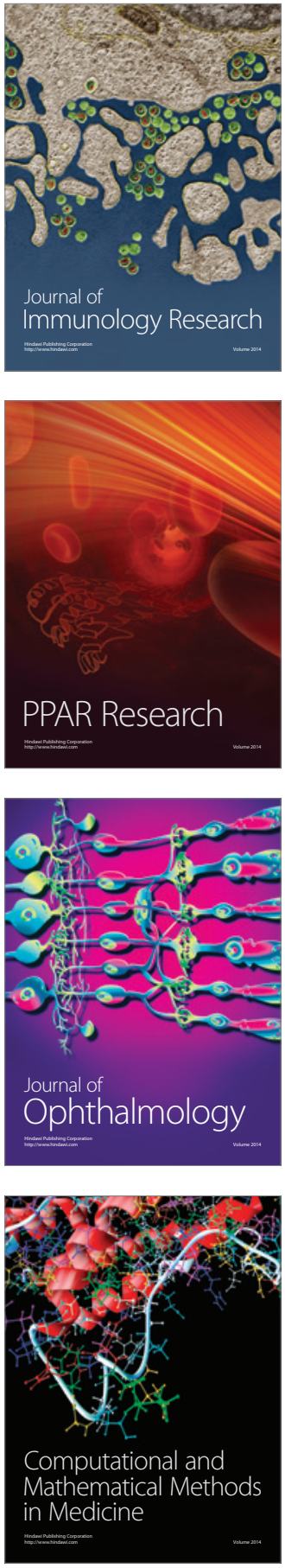

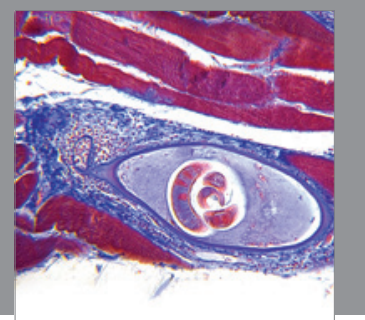

Gastroenterology

Research and Practice
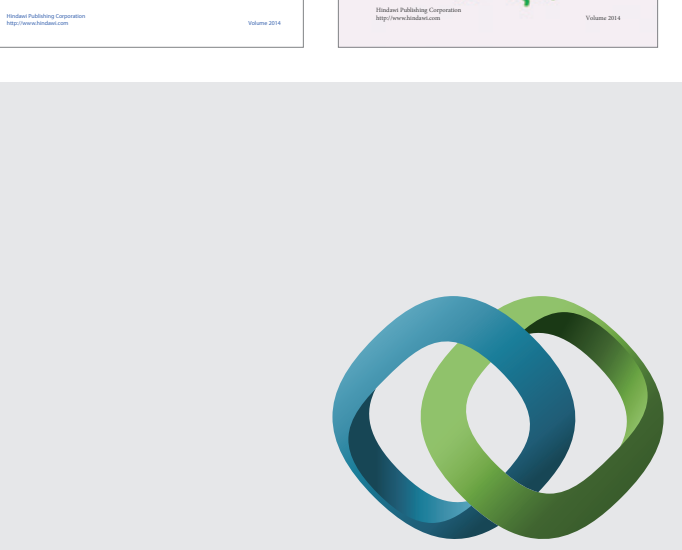

\section{Hindawi}

Submit your manuscripts at

http://www.hindawi.com
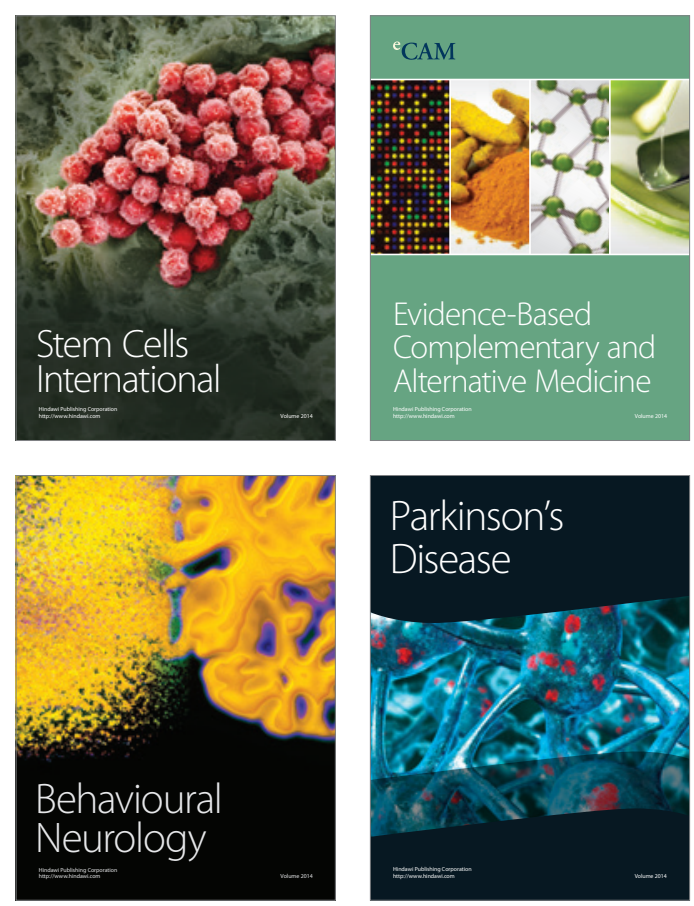

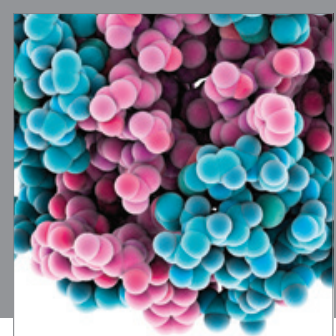

Journal of
Diabetes Research

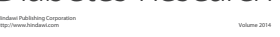

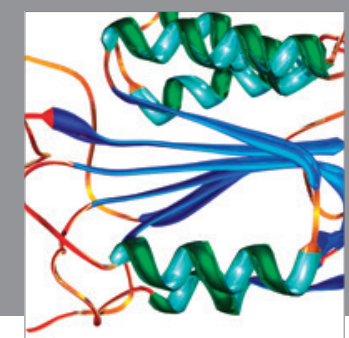

Disease Markers
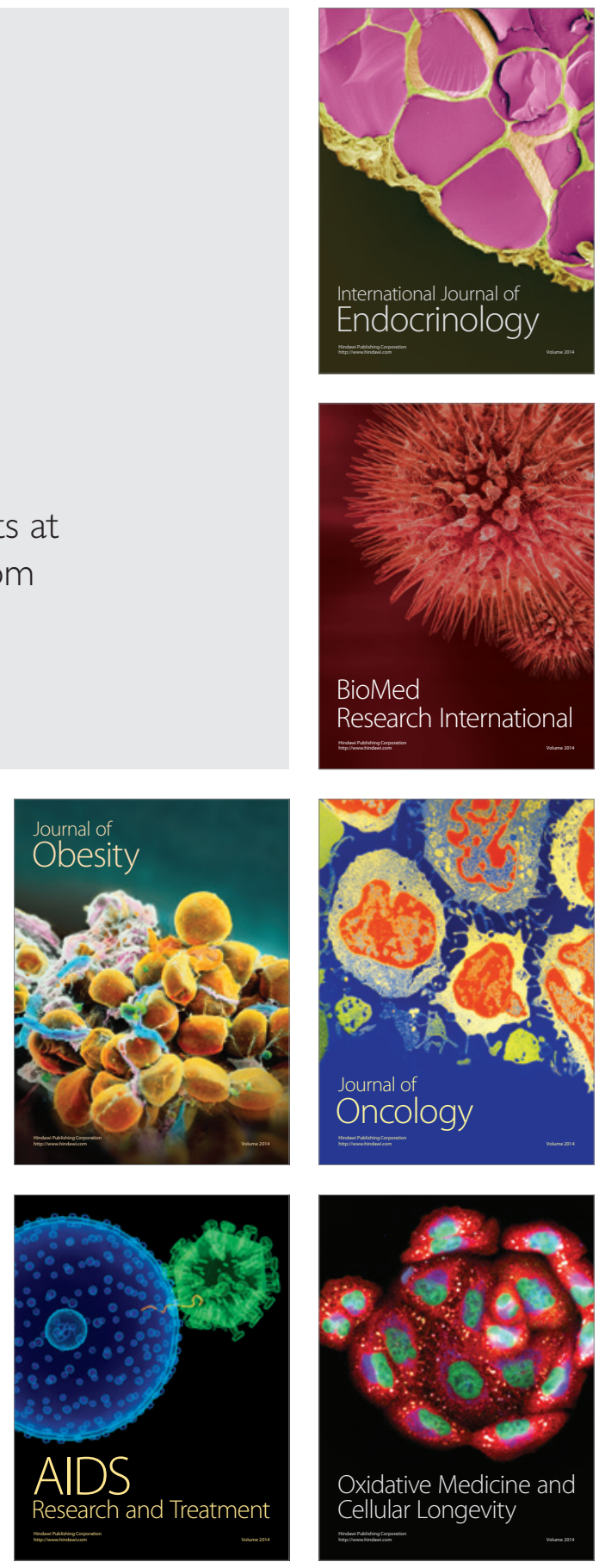